\title{
Using Logical Information Modelling in Solving the Cost Measurement Problem in the Economic Space
}

\author{
Tatyana Zhigulina ${ }^{1}{ }^{*}$ Valery Meretsky ${ }^{1}$
}

\author{
${ }^{1}$ Altai State Agrarian University, Russia \\ "Email: TNZhigulina@yandex.ru
}

\begin{abstract}
The article studies one of the persistent problems of economics - the problem of the cost measurement in the economic space. It has been found that the underlying features of the economic space - unevenness and cohesion - predetermine the essence of regional inequality: well-developed areas are scattered across the underdeveloped areas. The local markets with the centers formed in the development areas look as though they are inscribed into the economic space, and the properties circulating in such markets represent the development/underdevelopment level of the economic space by their cost parameters. In the underdeveloped economic space, the employment of the cost measurement method together with the principle of commensuration with the reference cost is not acceptable. The methodological approach to the logical information modeling-based resolution of the cost measurement problem of the economic space requires the involvement of the two measurement components: modeling-based and forecast-based determination of cost. These components may be applied both sequentially and independently from each other. The information theory-based approach implies the determination of the real estate property cost relying upon the complete/incomplete set of features identifying the cost category of the property and the cost forecast, done by extrapolation of the cost observation of other parts of the same economic space.
\end{abstract}

Keywords: Economic Space, Cost Measurement Problem, Logical Information Modeling, Region.

\section{INTRODUCTION}

Unevenness and cohesion are the underlying features of the economic space that determine the degree of its structural development. At the regional level, the unevenness of the economic space demonstrates itself through the combination of the development areas represented by agglomerations and other spatiallylocalized economic systems and the rest of the territory, or the underdeveloped area. Poliakova A.G., Simarova I.S. define the cohesion of the economic space as "spatial distribution of resources and achievement of an economic effect from their employment" [1]. At the regional level, these two effects predetermine the regional inequality that occurs there.

The local markets with the centers formed in the development areas look as though they are inscribed into the economic space, and the properties circulating in such markets represent the development/underdevelopment level of the economic space by their cost parameters.

According to the contemporary economic theory, the method of measuring the cost of an economic object in terms of money is referred to as assessment. The assessment process involves the comparison of the assessed property parameters with the reference properties with a known cost. However, in the inhomogeneous economic space, this cost measurement method applying is limited to a great extent, as it is possible only when the principle of commensuration with the reference cost is followed, and in the conditions of underdeveloped economic space, it is not applicable at all $[2,3]$.

In the case of under-development or poor development of the economic space, when the cost measurement is carried out in the situation of uncertainty, the most efficient measurement method is forecasting the cost parameters with the probability method.

\section{MODELS AND METHODS}

\subsection{Basic research methods}

The basic methods for this study were: observation and description, modeling and forecasting.

Observation and description. Based on the current researches analysis in the economic theory and spatial economics, the scientific problem of selecting the cost measurement method in the economic space, especially in the conditions of uneven development, has been 
formulated. In the studies of the cost measurement the object of research is the cost value.

Modeling and forecasting. The methodological approach to the logical information modeling-based resolution of the cost measurement problem of the economic space requires the involvement of the following two measurement components: modelingbased and forecast-based determination of cost. These components may be applied both sequentially and independently from each other.

The information theory-based approach implies the determination of the real estate property cost relying upon the complete/incomplete set of features identifying the cost category of the property and the cost forecast, done by extrapolation of the cost observation of other parts of the same economic space.

\subsection{Approbation of the method}

Logical information analysis has been successfully used in natural science studies, such as medicine, biology, edaphology, geography, etc. [4,5]; since recently, it has been used in technical science as well [6]. Concerning natural science studies, the algorithm has been described in detail in the work by Yu.G. Puzachenko and A.V. Moshkin [7].

In economics, and, particularly, the cost measurement, the method has been tested in the works by T.N. Zhigulina and co-authors within the last decade. There have been at least 15 published works that studied such aspects of the methodological approach as modeling the cost of real estate properties, local cost determination patterns, spatial forecast, approaches to improvement of the local real estate market functioning based on the indicative assessment [8-10].

This article is intended to conclude; having generalized the results achieved by various authors at different times, it formulates the final methodological approach to the problem set above.

\section{RESULTS AND DISCUSSIONS}

\subsection{Prerequisites of employment of the logical information modeling in the cost measurement}

Costs are unevenly distributed around the economic space; therefore, the price information in the real estate market is also unevenly distributed. On the one hand, this is a consequence of the projection of the inhomogeneity of the economic space to the market system; on the other, it reveals the imperfection of the market functioning mechanism, especially at a local level.

In these conditions, the price information is heterogeneous, with a large share of false data; it is inconsistent and spatially unevenly distributed.
Therefore, it may be supposed that the price formation in the real estate market is chaotic to a great extent, especially in the area where the covered areaterritory merges with a heterogeneous, incoherent part of the economic space. In such conditions, the assessment results depend on multiple unpredictable factors. This causes the stochastic character of their formation, which allows employing the logical information analysis algorithm in this research.

\subsection{Algorithm description}

So, let us consider a general case of cost measurement - cost assessment using the logical information analysis method.

Structurally, the algorithm consists of two parts: information and logical analysis, each of which is represented by two blocks (see fig. 1,2).

\subsubsection{Information analysis}

Data preparation block includes the development of the analytical table of the cross observations of the real estate cost: properties location and physical features (note, this set of argument factors is presented as an example only; cross observation may be carried out for the cost and other factors, belonging to the regional, national, or global levels). A distinctive feature of the logical information analysis is its capacity to analyze both quantitative (metrical) and attributive (qualitative) features, i.e. it does not require any metricity of data. Moreover, the method does not require the studied series to be subject to the Gaussian law, and the studied factors are not to be related to each other.

The analytical table is made up alongside with validation of the entries, filtering out the incomplete or doubtful data, the grouping of data based on these or those features. The research has shown that the input data can be grouped based on the economic zoning (division) at the stage of studying the morphology of the urbanized space. Data ranking includes the ranking of costs and the ranking of factors. The ranking is carried out for the metric indicators by determining the rank pitch as the variation range divided by the number of the ranks.

The common classifications of the factor parameters could be also used as a ranking. The attributive factors are ranked based on quality indicators.

The information analysis includes a consistent computation of an indicators series: probability, uncertainty, informativeness, information transmission efficiency coefficient based on the method [7]. In their 


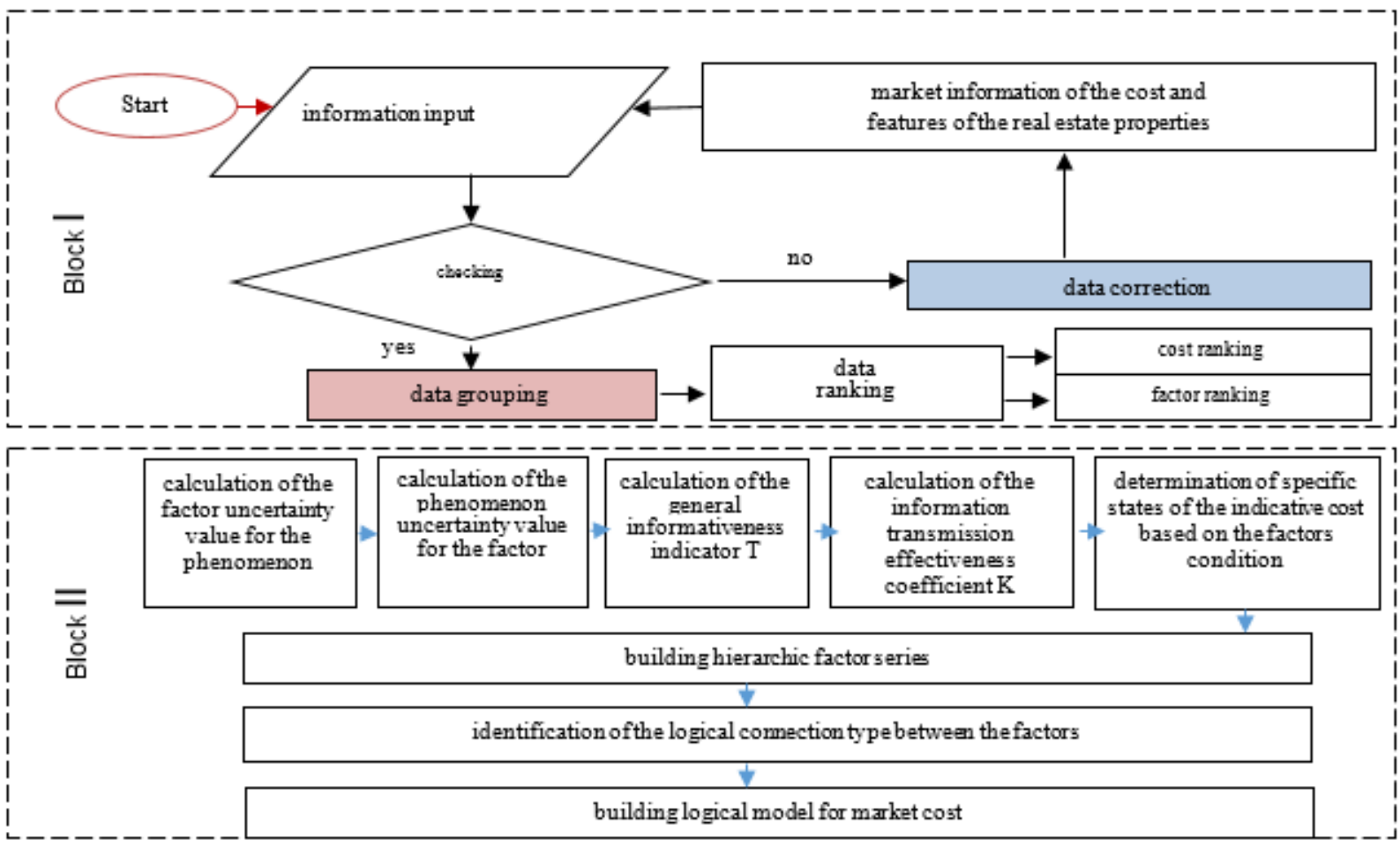

Figure 1 Information analysis algorithm.

work, Yu.G. Puzachenko, A.V. Moshkin write as follows: "without knowing the A distribution pattern, we may accept the phenomenon $a_{i}$ (of any value) to be a random event when the frequency of incidence of any rank $A=a_{i}$ is the assessment of conventional probability calculated as $p\left(a_{i}\right)=n_{a i} / N$, where $n$ is the number of incidence of $\mathrm{a}_{\mathrm{i}} ; \mathrm{N}$ is the total number of observations" [7].

The incidence of this or that value as a phenomenon (in our case, cost) or a factor (in our case, the priceforming factors) is, to some extent, uncertain:

$\mathrm{H}(\mathrm{A})=-\sum p_{a_{i}} \times \log _{2} p\left(a_{i}\right)$ where $\mathrm{H}(\mathrm{A})$ is the value of uncertainty or the phenomenon $\mathrm{A} ; \mathrm{H}(\mathrm{B})$ is the value of uncertainty for the argument-factor parameter (B). Function $\mathrm{p}(\mathrm{x})$ is operated based on the reference tables [7].

Based on the same method [7], the probability of ranks $a_{1}, a_{2} \ldots a_{K}$ is calculated; in every rank $B$, it is determined as $p\left(a_{i} / b_{j}\right)$. For every $b_{j}$, the uncertainty value is calculated:

$\mathrm{H}\left(\mathrm{a}_{\mathrm{i}} / \mathrm{b}_{\mathrm{j}}\right)=-\sum p\left(a_{i} / b_{j}\right) \times \log _{2} p\left(a_{i} / b_{j}\right)$

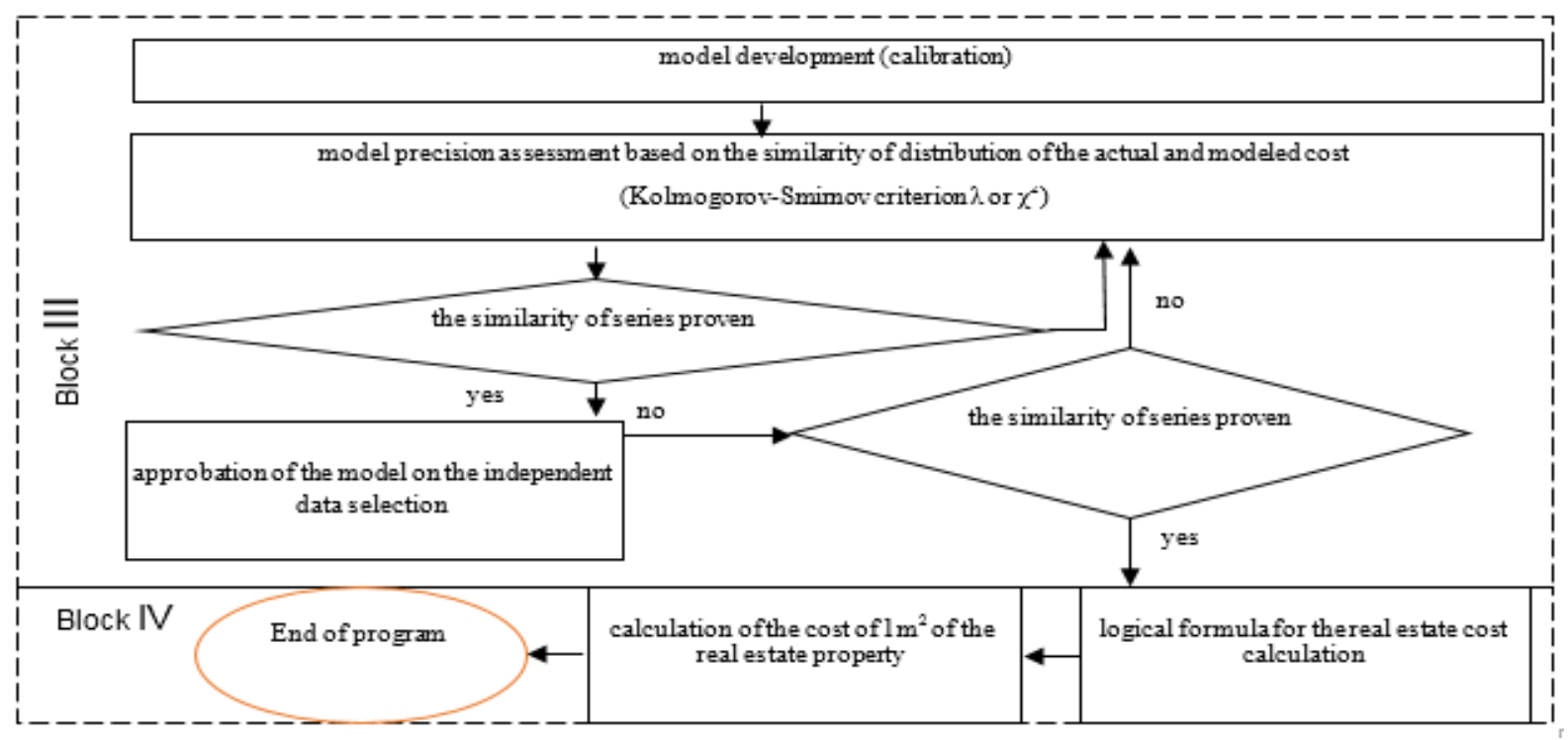

Figure 2 Logical analysis algorithm. 
If phenomenon $\mathrm{A}$ and $\mathrm{B}$ are interdependent, then $\mathrm{H}(\mathrm{A}) \neq \mathrm{H}\left(\mathrm{a}_{\mathrm{i}} / \mathrm{b}_{\mathrm{j}}\right)$. The difference between these values is $\mathrm{J}\left(\mathrm{A} / \mathrm{b}_{\mathrm{j}}\right)$ information from $\mathrm{A}$ contained in $\mathrm{b}_{\mathrm{j}}$. The amount of information transmitted from parameter $\mathrm{B}$ to phenomenon $A$ is assessed as a sum of products of the $b_{j}$ probability rank and the amount of information contained in the rank, denoted by $\mathrm{T}(\mathrm{A}, \mathrm{B})$.

The value $\mathrm{T}(\mathrm{A}, \mathrm{B})$ depends not only on the relation between $\mathrm{A}$ and $\mathrm{B}$ but also their uncertainty values $(\mathrm{H})$. To mitigate the influence of the $\mathrm{H}$ value, the coefficient of efficiency of the information transmission by the argument factor $\mathrm{B}$ to the function phenomenon $\mathrm{A}$ is introduced. It is calculated with the formula $\mathrm{K}(\mathrm{A}, \mathrm{B})=$ $\mathrm{T}(\mathrm{A}, \mathrm{B}) / \mathrm{H}(\mathrm{B})$ [7].

The information transmission efficiency coefficient is maximal when the parameter transmits to the phenomenon the amount of information that equals the minimum uncertainty. The most relevant (leading factor) parameter is the one with the highest $\mathrm{K}$ coefficient. Therefore, $\mathrm{K}$ may be used to determine the degree of influence which every factor may make on the studied phenomenon, and to rank the studied factors by their degree on the influence on the cost value in a hierarchic series, such as

$\mathrm{C}=\frac{\text { ТД }}{0,2919}>\frac{\text { ГП }}{0,2469}>\frac{\text { ТК }}{0,2410}>\frac{\text { СК }}{0,2343}>\frac{\% И}{0,1906}>\frac{\mathrm{S}}{0,1740}>$ $\frac{\mathrm{MC}}{0,0942}>\frac{\mathrm{KK}}{0,0933}>\frac{\ni}{0,0790}$

where $\mathrm{C}$ is the market price of $1 \mathrm{~m} 2$ of multi-storeyed accommodation estate, ТД is the house type, ГП is the year of construction of the house, ТК is the room type, $\mathrm{CK}$ is the condition of the apartment, $\% И$ is the house depreciation percentage, $\mathrm{S}$ is the floor area of the apartment, $\mathrm{MC}$ is the wall material, $\mathrm{KK}$ is the number of the rooms and $\ni$ is the floor.
The result of the information analysis part is the developed analytical matrix of the specific conditions of the cost (tab.1).

The specific conditions characterize the most probable value of the cost at different conditions of the factor parameters. They are determined by the value of the coefficient of relation $(\mathrm{C})$ of the specific probability of incidence of the number of observation points in a rank to the general probability of the rank, calculated with the formula $\mathrm{C}=\mathrm{p}(\mathrm{ai} / \mathrm{bj}) / \mathrm{p}$ (ai), where $\mathrm{C}$ is the relation coefficient; $p$ ( $a i / b j$ ) is the conventional probability of the condition $i$ of the offer price at the $j$ condition of the factor; $\mathrm{p}(\mathrm{ai})$ is the general probability of the incidence of the offer price in the given factor rank. At that, it should be remarked that the specific conditions present the dependency that would take place in the event of the influence of one separately given factor [7].

\subsubsection{Logical analysis}

Model development (calibration) is the selective logical adjustment of factors to make a series of consistent modifications and formula. A similar series distribution for the actual and modeled (estimated) cost is studied for each of them with the KolmogorovSmirnov $(\lambda)$ or the Pearson criterion $(\mathrm{x} 2)$. A positive result is the coincidence of the estimated and modeled costs rank by rank and an insignificant deviation by one rank. $\lambda$ criterion should remain below the value of 1.36 , corresponding to the probability of 0.95 . After calibration of the model based on the data used for its development, the model is tested on some independent data.

Example of a logical formula for determining the cost of $1 \mathrm{~m}^{2}$ of accommodation estate for the local price zone of the city:

Table 1. Specific states of the cost value for the state of the price formation factor parameters in the local price zone (fragment)

\begin{tabular}{|l|l|c|c|}
\hline \multicolumn{1}{|c|}{ Factor } & \multicolumn{1}{c|}{$\begin{array}{c}\text { Condition of } \\
\text { factor }\end{array}$} & $\begin{array}{c}\text { Cost value 1 m2, thousand } \\
\text { roubles }\end{array}$ & Rank \\
\hline Room type & walkthrough & $40.0-41.9$ & 6 \\
$T=0.2229$ byte & walkthrough-isolated rooms & $40.0-41.9$ & 6 \\
$\mathrm{~K}=0.2410$ & isolated & $46.0-47.9$ & 9 \\
\hline Apartment condition & satisfactory & $36.0-39.9$ & $4-5$ \\
$\mathrm{~T}=0.3163$ & good & $42.0-45.9$ & $7-8$ \\
$\mathrm{~K}=0.2343$ & excellent & $50.0-53.9$ & $11-12$ \\
\hline House depreciation rate, \% & $<10$ & $50.0-53.9$ & $11-12$ \\
$\mathrm{~T}=0.3622$ & $11-20$ & $40.0-41.9$ & 6 \\
$\mathrm{~K}=0.1906$ & $21-30$ & $42.0-45.9$ & $7-8$ \\
& $31-40$ & $36.0-37.9$ & 4 \\
& $41-50$ & $34.0-37.9$ & $3-4$ \\
\hline
\end{tabular}




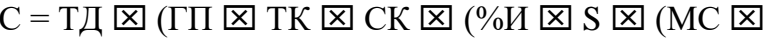 КК $囚 ~ Э)))$ \\ with the same legend as for the formula (3) \\ $凶$ is the sign of non-linear logical product}

The using capacity of the studied methodological approach for the cost measurement of economic space through assessment (modeling) of the cost is demonstrated in detail in the previous paragraph; according to the authors, it requires no additional explanations.

Within the described problem, the method of cost measurement through the forecast of the cost based on an incomplete set of argument factors is of special interest. For this purpose, it is necessary to expand the scale of the specific conditions of the argument factors to its upper or lower values to cover all the parameters of the argument factors.

\section{CONCLUSION}

As a result of the study, the following conclusions were made:

It has been found that the underlying features of the economic space - unevenness and cohesion predetermine the essence of regional inequality: welldeveloped areas are scattered across the underdeveloped areas. The local markets with the centers formed in the development areas look as though they are inscribed into the economic space, and the properties circulating in such markets represent the level of

development/underdevelopment of the economic space by their cost parameters.

Using the existing economic space cost measurement method on the commensuration means with a reference cost in the conditions of heterogeneous space is limited to a great extent, and in an underdeveloped economic space, it is not applicable at all.

In the case of under-development or poor development of the economic space, when the cost measurement is carried out in the situation of uncertainty, the most efficient measurement method is forecasting the cost parameters with the probability method.

\section{REFERENCES}

[1] A.G. Poliakova, I.S. Simarova, Managing the regional development of the West Siberia with respect to the coherence of its economic space, State and municipal management 3 (2014) 141-161.

[2] N.V. Ivanova, Mechanisms of the network redevelopment of the agro-economic space of Russian regions. Reg. Res. Russ. 4 (2014) 335-340. DOI: https://doi.org/10.1134/S2079970514040248
[3] T. Puu, On the Art of Successful Analogy Formation: Martin Beckmann's Continuous Model of Economic Space. In: Hauptmann H., Krelle W., Mosler K.C. (eds) Operations Research and Economic Theory. Springer, Berlin, Heidelberg, 1984. DOI: https://doi.org/10.1007/978-3-64269909-2 13

[4] L.M. Burlakova, Fertility of the Altai Black Soils in the Farm Ecosystem. Nauka: Siberian Branch, Novosibirsk, 1984.

[5] Yu.G. Puzachenko, Mathematical Methods in Environmental and Geographical Studies, Academia, Moscow, 2004

[6] S.O. Khomutov, V.G. Tonkikh, Applying the Logical Information Analysis for the Studies of Impact of the Defects of the Asynchronous Engine on the Spectrum of Its Outer Magnetic Field. In: Mayer, G.V., Bashkatov, V.Z. (eds.) Social, Information, and Energy Problems of the Region, Tomsk State University Newsletter, Current Scientific Information Bulletin, TSU, Tomsk Vol. 82 (2006) 32-38.

[7] Yu.G. Puzachenko, A.V. Moshkin, Logical Information Analysis in the Medical and Geographic Research. In: Scientific Conclusions Issue 3 (1969) 5-74, All-Union Institute of Scientific and Research Information, Moscow.

[8] T.N. Zhigulina, Feasibility of the Market Cost of a Multi-Storeyed Accommodation Real Estate of Barnaul Town, Altai State Agrarian University Newsletter 11(85) (2011) 127-131.

[9] T.N. Zhigulina, V.A. Meretsky, Feasibility of the Indicative Approach to the Massive Evaluation of the Accommodation Real Estate in the Local Real Estate Market Functioning Management System. In: collection of articles of the 7th International Scientific and Practical Conference "Agrarian Science to Agriculture", ASAU, Barnaul Vol. 1 (2012) 160-162.

[10] T.N. Zhigulina, V.A. Kundius, Development of the Massive Real Estate and Land Plot Evaluation Institution in the Accommodation Real Estate System of the Region, Azbuka, 2012. 